\title{
Experimental determination of contraction coefficient and velocity coefficient for radial gates with elliptical lips
}

\author{
JAILAKSHMI MENON* and B V MUDGAL \\ Centre for Water Resources, Anna University, Chennai 600025, India \\ e-mail: jailakshmim@yahoo.co.in; bvmudgal@gmail.com
}

MS received 19 November 2016; revised 28 June 2017; accepted 4 January 2018; published online 16 April 2018

\begin{abstract}
Radial gates are widely used to control the flow in irrigation channels and spillways. Radial gates require lower hoisting force and have better discharge characteristics in partial gate openings. The accurate discharge measurement through a radial gate is a challenging problem especially in submerged flow conditions. The coefficient of contraction $C_{c}$ is an important parameter for accurate discharge measurement in open channels. In this study, an attempt has been made to determine the coefficient of contraction $C_{c}$ and velocity coefficient $C_{v}$ for radial gates both for free flow and submerged flow conditions. The flow emanating from a gate is similar to the wall jet emerging from a nozzle. The $C_{c}$ and $C_{v}$ values under free and submerged flow conditions are obtained from the measured jet velocity and the discharge. The coefficient of discharge values under submerged flow conditions show large variations with submergence and hence discharge characteristics needs to be improved for better control of flow. Hence, experiments are conducted so as to improve the discharge characteristics by modifying the exit geometry of the radial gate by attaching a quarter of an elliptical lip. Three different geometries of elliptical lips were attempted and the results show reasonable increase in the contraction coefficient.
\end{abstract}

Keywords. Radial gates; contraction coefficient; wall jet; acoustic doppler velocimeter (ADV); laboratory experiments.

\section{Introduction}

Sluice gates are used as structures to control the head (depth of flow) and discharge in channels and over spillways. Accurate determination of discharge through a gate has been posing difficulties especially for the submerged flow conditions in channels. Numerous literatures are available on experiments with sluice gates but most of them deal with vertical gates. Radial gates are a good replacement for vertical sluice gates because of their ease in operation due to the resultant force passing through the centre of curvature. The discharge through a sluice gate is independent of the tail water depth in free flow conditions but depends on both upstream and downstream water depths in submerged flow conditions.

A relationship between the discharge coefficient and the upstream water depth for a vertical sluice gate assuming hydrostatic pressure distribution was developed [1]. The energy losses were assumed to be negligible. The free and submerged flow conditions through vertical sluice gates were later investigated and the authors have recommended values for coefficient of contraction [2]. The equations proposed for computing the discharge coefficient under free

*For correspondence and submerged flow conditions were modified using regression analysis [3]. The discrepancies in the values of contraction coefficient between the experimental method and the numerical methods were examined [4]. The energy losses due to the vortex developed on the upstream of the gate was thought to be the reason for the variation in the contraction coefficient. The concept of incomplete selfsimilarity was used to develop a stage discharge relationship for a flow over and under a broad crested weir and a sluice gate under free flow conditions [5]. Later the author extended his work to submerged flow conditions as well [6]. The distinguishing condition (i.e., the condition for maximum possible tail water depth) for free and submerged flow for vertical sluice gates was developed [7]. The contraction coefficient was incorporated to derive the discharge coefficient and maximum gate opening possible for sluice gates. The different calibration methods were tested and the author concluded that the energy momentum method and the conventional discharge equation performed well [8]. A theoretical framework based on energy and momentum conservation to compute coefficient of discharge in free flow and submerged flow conditions for vertical sluice gates was developed [9]. The accuracy of different methods of sluice gate calibration using laboratory data was compared [10] and they concluded that the best results were 
obtained by the method proposed in [5]. Numerical techniques were employed to investigate the flow characteristics upstream and downstream of the gate and it was observed that the contraction coefficient varied with the gate opening and the submergence [11]. The effect of highly non uniform velocity profiles downstream of the gate was accounted by introducing suitable energy and momentum correction coefficients [12]. The importance of energy loss on the discharge characteristics of vertical sluice gates was emphasized and a new equation for incorporating the losses was proposed [13].

Not many works have been reported for radial gates in comparison with vertical gates. The experiments on radial gates were conducted extensively [14] and the author developed the computer program RADGAT for its calibration. Energy-momentum method was used to calibrate the radial gates under free and submerged flow conditions [15]. A kinetic energy correction factor was applied for transition to submerged flow. The contraction coefficient was obtained by measuring the pressure in the jet at the vena-contracta with a Prandtl tube. The energy correction factor proposed in [15] was modified and employed to analyse and verify Buyalski's experimental data [16]. A dimensionless head discharge relationship for radial gates using the indicial method of dimensional analysis was formulated [17]. They also examined the effect of Reynolds number on discharge. A new stage discharge relationship applying the incomplete self similarity concept for radial gates was developed [18]. The existing radial gate design was modified by relocating the gate hinges and attaching a semicircular cylinder at the bottom so as to standardize the exit jets. The new design improved the accuracy in discharge measurement in underflow and overflow gates [19].

The present work deals with experimental investigations on radial gates. The exact location of the vena-contracta under radial gates is very difficult in practical situations and hence the measurement of jet thickness will not be accurate. In this study, the coefficient of contraction $C_{c}$ is obtained indirectly by using the concept of constant velocity at the vena-contracta equal to the velocity in the potential core region of the wall jet [20]. The measured jet velocity $v_{j}$ was used to obtain the coefficient of velocity $C_{v}$. The discharge characteristics depends on the coefficient of contraction. The coefficient of contraction depends on the gate opening, the water level upstream of the gate and the pinion height of the gate. $C_{c}$ values depends on the curvature of the streamlines which inturn is a function of the gate angle $(\theta)$ (figure 1). As the gate angle approaches zero, the $C_{c}$ values tend to become unity. This will result in constant discharge characteristics both in free and submerged flow conditions. Hence an attempt is made to improve the discharge characteristics by modifying the exit. The experiments were carried out in the Fluid Mechanics Laboratory, Centre for Water Resources, Anna University, India and compared with the previous work on radial gates.

\subsection{Methodology}

Figure 1 shows the schematic sketch of free and submerged flow conditions through a radial gate. The flow through a sluice gate resembles that of a wall jet emanating from the nozzle. For a flow through a gate, there exists a region of vena-contracta in which the area is minimum, the streamlines are parallel and the velocity is uniform. The potential core of the wall jet which begins from vena-contracta, is the region in the jet in which the velocity remains essentially constant and equal to the velocity at the nozzle exit. In the horizontal direction it extends to a length of about 6 times the nozzle opening [20] as depicted in figure 2. Hence the jet velocity $v_{j}$ is determined by the maximum velocity in the potential core region.

The relationship between the jet velocity and the depth upstream of the gate in free flow is given by

$$
v_{j}=C_{v} \sqrt{2 g y_{1}}
$$

where $v_{j}$ is the jet velocity; $C_{v}$ is the coefficient of velocity; and $y_{1}$ is the upstream water depth

The jet velocity under submerged flow conditions can be expressed as

$$
v_{j}=C_{v} \sqrt{2 g\left(y_{1}-y_{2}\right)}
$$

where $v_{j}$ is the jet velocity; $C_{V}$ is the coefficient of velocity; $y_{1}$ is the upstream depth; $y_{2}$ is the downstream depth at the exit of the gate. The measured jet velocity $v_{j}$ and the water depth upstream and downstream of the gate are used to determine the coefficient of velocity $C_{v}$.

The upstream energy head $\left(H_{1}\right)$ under free flow conditions is determined using the energy equation

$$
H_{1}=y_{1}+\frac{v_{1}^{2}}{2 g}
$$

where $y_{1}$ is the upstream water level measured with a pointer gauge with least count of $0.1 \mathrm{~mm}, v_{1}$ is the average velocity upstream of the gate. The energy losses encountered is computed using the Bernoulli's equation for both free and submerged flow conditions.

The coefficient of contraction $\left(C_{c}\right)$ is defined as the ratio of area of water at vena-contracta $\left(\mathrm{L} * \mathrm{y}_{\mathrm{j}}\right)$ to the area at gate opening $(\mathrm{L} *$ a).With reference to figure 1 ,

$$
Q_{a c t}=A_{a c t} * V_{a c t}=\left(y_{j} * L\right) * v_{j}=\left(C_{c} * a * L\right) * v_{j}
$$

where $Q_{a c t}$ is the actual discharge in the flume and $v_{j}$ is the jet velocity.Applying the equation of continuity, the coefficient of contraction $C_{c}$ can be expressed as

$$
C_{c}=\frac{Q_{a c t}}{L * a * v_{j}}
$$

The coefficient of contraction $C_{c}$ is determined from the measured jet velocity and the discharge. $C_{c}$ is a function of 


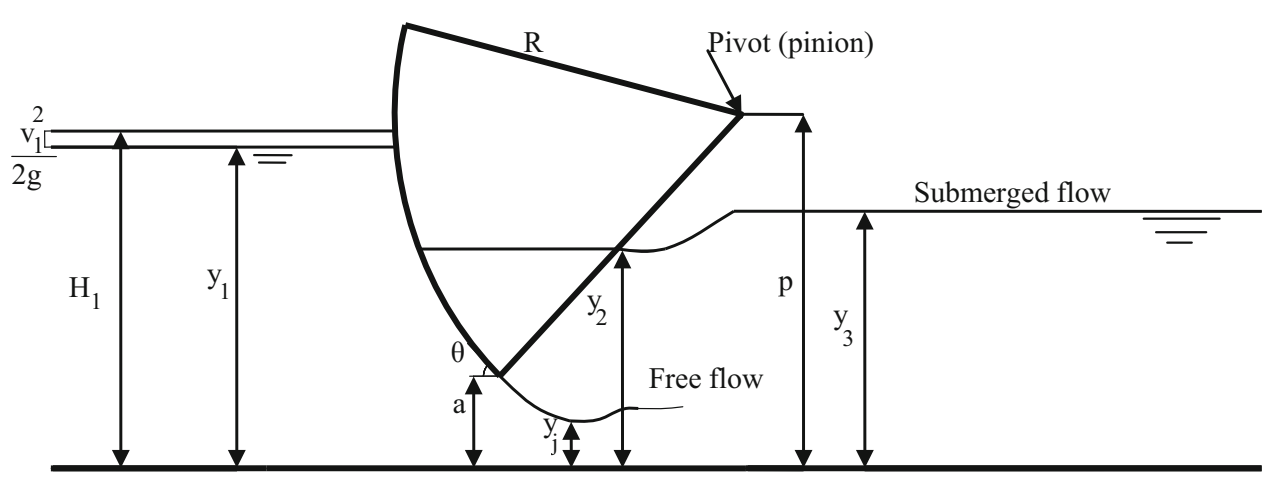

Figure 1. Schematic representation of a radial gate.

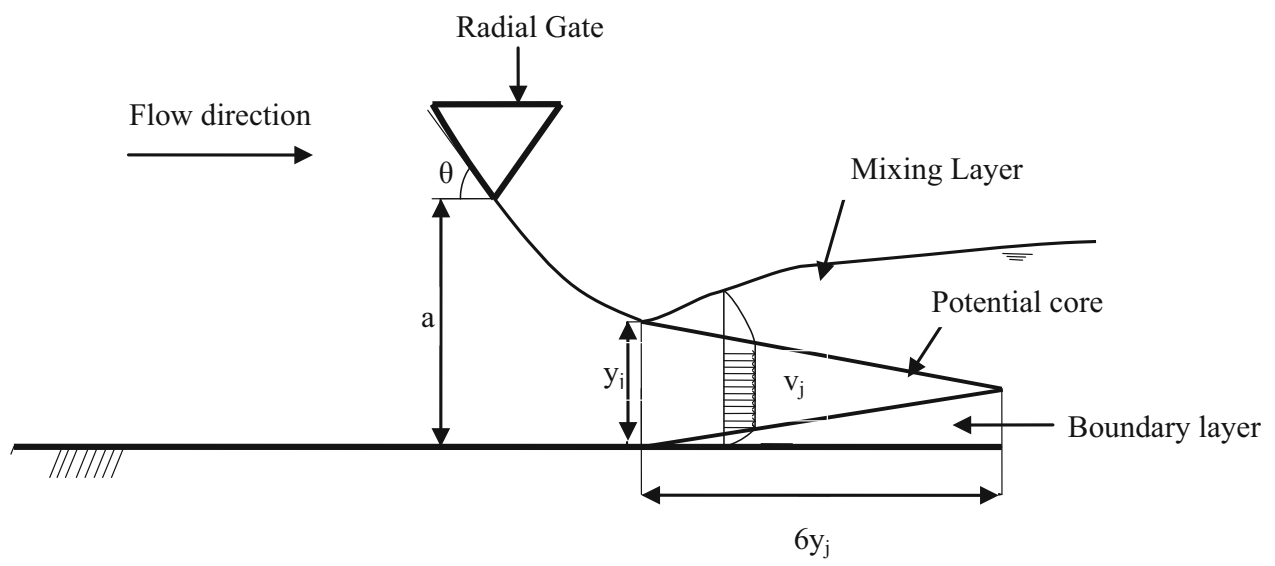

Figure 2. Schematic representation of the Flow conditions at the exit of the radial gate.

the gate angle $\theta$ of the radial gate and is given by Tel's equation [21], (Eq. 6).

$$
C_{c}=1.001-0.2349 \theta-0.1843 \theta^{2}+0.1133 \theta^{3}
$$

\subsection{Modification in radial gate design}

The existing radial gate design was modified with the intention of increasing the coefficient of contraction. The modification in the exit decreases the gate angle and hence improves the coefficient of contraction values. This will help in accurate discharge measurement in free and submerged flow conditions. Accordingly quadrant of an ellipse was attached at the lip of the radial gate. The schematic diagram of the quadrant is shown in figure 3 . Three different geometries of the quadrant of an ellipse were tested. The ratios of the semi major axis to semi minor axis for the three geometries are 1:1, 2:1 and 3:1. The ratio of the semi major axis of the quadrant lip attached to the radius of the gate (d:R) attempted in this study were $1: 10,1: 5$ and $1: 3.33$.

\section{Experimental set-up}

Experiments were conducted in a tilting flume $6.4 \mathrm{~m}$ long, $0.324 \mathrm{~m}$ wide and $0.5 \mathrm{~m}$ high. The walls were of glass and the bed was made of acrylic material. The flume was adjusted to have zero slope during the conduct of the experiment. The water from the sump is pumped using a $23 \mathrm{~kW}$ motor. The discharge in the flume was measured using a calibrated venturimeter.

The venturimeter readings were cross checked with the Rehbock weir formula. A suppressed weir of height $15 \mathrm{~cm}$ was fixed at the downstream end of the flume so as to calculate the actual discharge flowing through the flume. The discharge passing over the weir is calculated using weir formula,

$$
Q_{a c t}=\frac{2}{3} C_{d w} \sqrt{2 g} H_{w}^{\frac{3}{2}} L
$$

where $Q_{a c t}$ is the actual discharge in $\mathrm{m}^{3} / \mathrm{s} ; H_{w}$ the head over the crest of the weir; $L$ the length of the weir; $C_{d w}$ the coefficient of discharge for the weir which is given by Rehbock formula, 


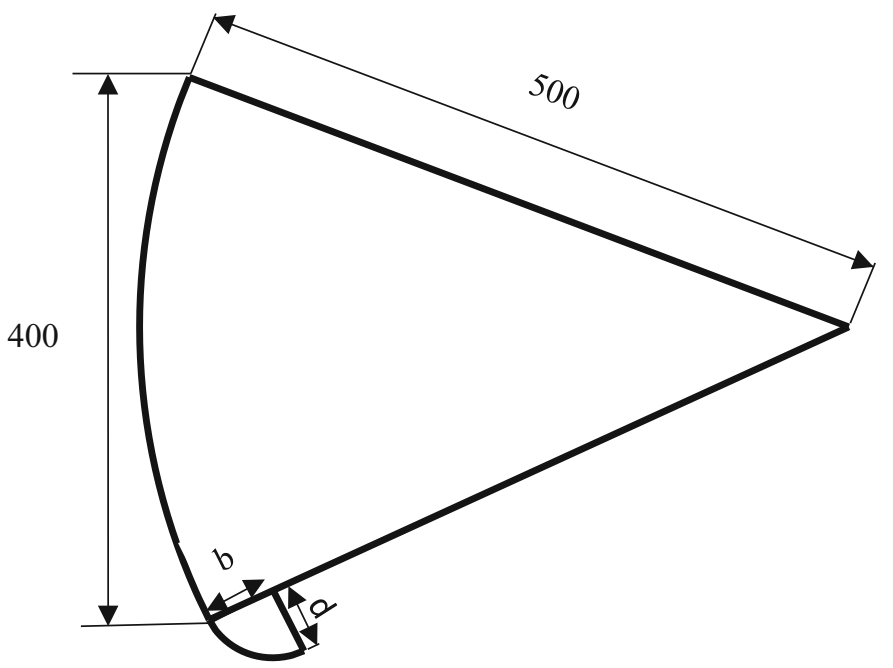

$\begin{array}{ccc}\text { Geometry } & \text { b } & \text { d } \\ 1 & 50 & 50 \\ 2 & 50 & 100 \\ 3 & 50 & 150\end{array}$

All dimensions in $\mathrm{mm}$

Figure 3. Dimensions of the modified radial gate.

$$
C_{d w}=0.611+0.08 \frac{H_{w}}{P}
$$

where $P$ is the height of the weir.

The equation for the discharge through the venturimeter has been calibrated and it is given by

$$
Q_{a c t}=0.105 H^{0.51}
$$

where $H$ is the difference in manometer readings in the U-tube manometer in m of mercury.

A radial gate of radius $50 \mathrm{~cm}$ and vertical height $40 \mathrm{~cm}$ was fabricated in acrylic material and installed in the tilting flume. The schematic sketch of the experimental set-up is depicted in figure 4 . The trunnion height of the gate (p) was set at $20 \mathrm{~cm}$ from the floor of the flume for the initial runs of the experiment. The gate opening was set and accurately measured. Once the flow was stabilized, the water level upstream of the gate $\left(y_{1}\right)$ was measured using the pointer gauge accurate to $0.1 \mathrm{~mm}$. The velocity $v_{j}$ at the venacontracta was measured with an acoustic Doppler velocimeter (Vectrino make from Nortek).

In this study a side looking ADV of Nortek make is used. ADV is a single point, high resolution Doppler current meter which provides 3-D velocity measurements in a remotely sample volume. The transducers are mounted such that their beams intersect over a volume located at 5 $\mathrm{cm}$ from the probe, called sampling volume. The location of the sampling volume is at $7 \mathrm{~mm}$ from the bottom of the ADV. The sampling rate is $200 \mathrm{~Hz}$ and the velocity range was set at $2.5 \mathrm{~m} / \mathrm{s}$. The time of sampling used was $1 \mathrm{~min}$. The measuring volume of the ADV was located within the potential core of the jet. The velocity measurements were made in a vertical section at $7 \mathrm{~mm}$ from the bottom of the flume and thereafter at intervals of $5 \mathrm{~mm}$ till the free surface of water. The accuracy in the readings was ensured by keeping the signal to noise ratio greater than 25 [22]. The

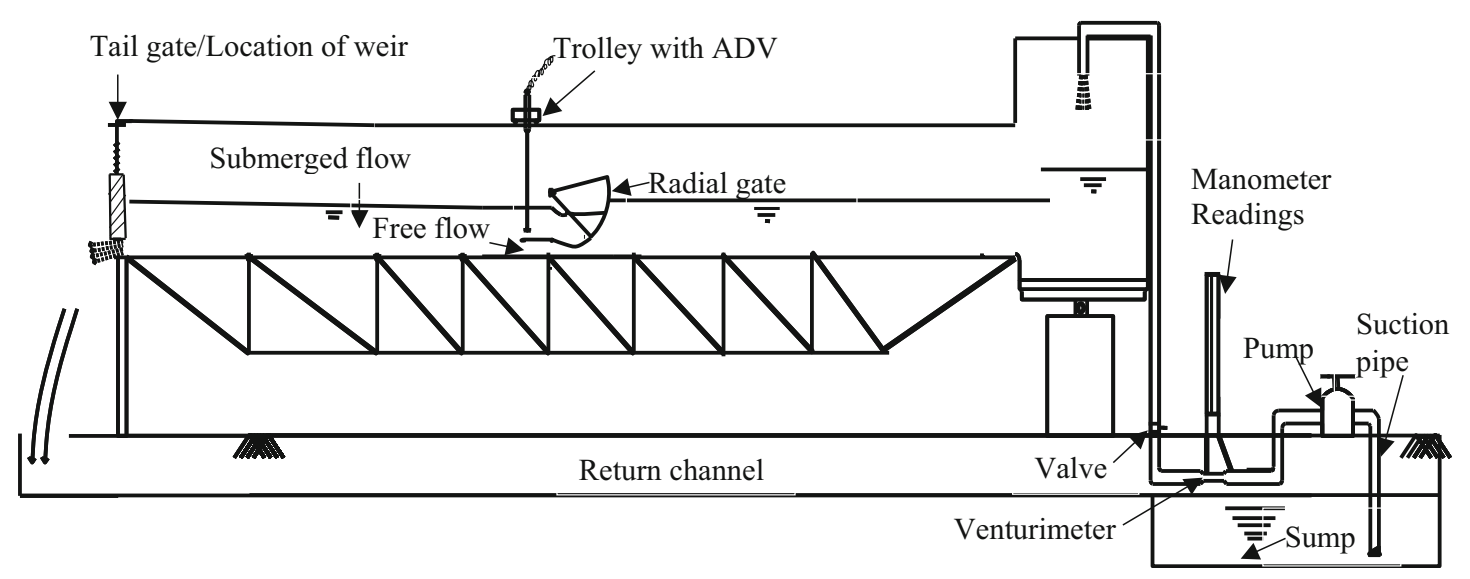

Figure 4. Schematic sketch of the experimental setup. 
velocity in the potential core is constant and it is also taken to be the jet velocity $v_{j}$. Experiments were conducted for 15 runs in free flow conditions. Figure 5 shows the velocity profile immediately downstream of the radial gate (measured using ADV within the potential core length) with $7 \mathrm{~cm}$ gate opening and a discharge of $0.019 \mathrm{~m}^{3} / \mathrm{s}$. From the graph the maximum velocity is $1.5 \mathrm{~m} / \mathrm{s}$ and the same is taken as jet velocity. Similar procedure is followed for radial gates with elliptical lips as well.

The experimental set-up for submerged flow conditions included a movable vertical tail gate installed at the downstream end of the flume to vary the submergence. After the flow has stabilized for free flow conditions the readings were taken and then the downstream gate was slowly lowered to make the gate submerged. Once the flow has stabilized for the submerged condition the upstream depth $\left(y_{1}\right)$, the depth downstream at the exit of the gate $\left(y_{2}\right)$ and the tail water depth $\left(y_{3}\right)$ of flow were measured using pointer gauges. The velocity was also measured using ADV in the potential core region. The submergence ratio was varied by further lowering/raising the vertical gate at the downstream end. Experiments were repeated for 42 runs in submerged flow conditions. Experiments were conducted with the modified gate for both free and submerged flow conditions for two different trunnion heights (p) of 24 and $34 \mathrm{~cm}$. The details of different experimental runs for free and submerged flow conditions are listed in table 1.

\section{Results and discussions}

\subsection{Contraction coefficient in free flow}

Figure 6 compares the variation of $C_{c}$ obtained experimentally with those obtained using Tel's equation (6) for radial gate under free flow conditions. The results show a variation of $\pm 10 \%$ in the computed $C_{c}$ values when compared with the values obtained using Tel's equation. This may be attributed to the different $(\mathrm{p} / \mathrm{R})$ ratios in Tel's and present experiments.

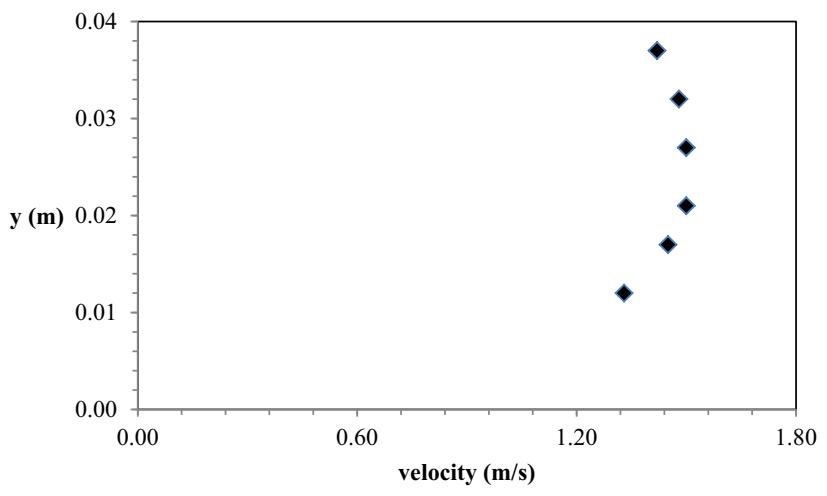

Figure 5. Velocity profile downstream of the gate.
Table 1. Ranges of discharge (Q) and gate opening (a) for the gates.

\begin{tabular}{lccc}
\hline Gate & Flow condition & Gate opening $(\mathrm{a})(\mathrm{cm})$ & $\mathrm{Q}(1 / \mathrm{s})$ \\
\hline Radial gate & Free & $5-8$ & $8-40$ \\
Radial gate & Submerged & $5-8$ & $5-25$ \\
Geometry 1 & Free & $5-8$ & $18-39$ \\
& Submerged & $5-8$ & $20-30$ \\
Geometry 2 & Free & $5-8$ & $18-39$ \\
& Submerged & $5-8$ & $18-40$ \\
Geometry 3 & Free & $5-8$ & $18-39$ \\
& Submerged & $5-8$ & $18-32$ \\
\hline
\end{tabular}

The variation of $C_{c}$ with relative gate opening $\left(\mathrm{a} / \mathrm{y}_{1}\right)$ for radial gate in free flow conditions is shown in figure 7 . The $C_{c}$ values decrease with increase in the gate opening. The trend resembles the results from previous works on vertical sluice gates [9]. The $C_{c}$ values show reasonable increase due to the addition of quadrant of an ellipse at the exit of the gate. The increase in $C_{c}$ is more for the modified gate with the geometry 2 . This can be justified with the fact that the gate angle approaches zero in the second case and correspondingly the $C_{c}$ values attain a range of $0.85-0.92$. The quadrant of an ellipse acts as a converging nozzle and helps in streamlining the flow. This results in an increase in the value of $C_{c}$.

\subsection{Coefficient of velocity in free flow}

Figure 8 shows the variation in jet velocity with the upstream depth of flow in free flow conditions. With reference to figure 8 , the jet velocity for the observed values for free flow is given by

$$
\frac{v_{j}^{2}}{2 g}=0.787 * y_{1}
$$

From Eq. (10), the coefficient of velocity is found to be 0.89 .

Following the method proposed in [15], the combined velocity distribution coefficient and energy loss coefficient in free flow conditions for radial gate was calculated using the energy equation applied between the upstream of the gate and the vena-contracta.

$$
H_{1}=y_{j}+\propto \frac{v_{j}^{2}}{2 g}+\beta \frac{v_{j}^{2}}{2 g}
$$

where $H_{1}$ is the upstream energy head; $v_{j}$ is the jet velocity; $\alpha$ is the velocity distribution coefficient; and $\beta$ is the energy loss coefficient.

The computed value of the sum of the coeffcients $(\alpha+\beta)$ for free flow varied from 1.06 to 1.15 . Assuming the velocity distribution coefficient $(\alpha)$ to be unity, the combined coefficient can be expressed as $(1+\beta)$. Figure 9 


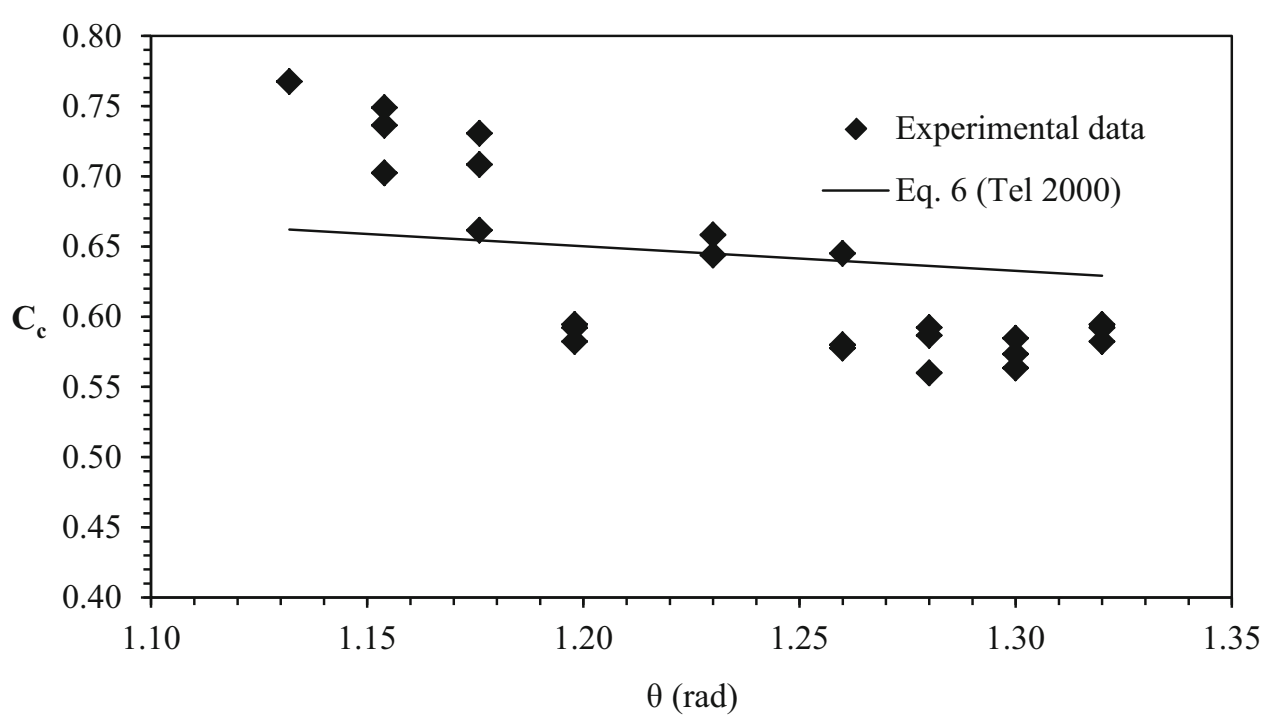

Figure 6. Variation of coefficient of contraction $\left(\mathrm{C}_{\mathrm{c}}\right)$ with gate angle $\theta$ in free flow.

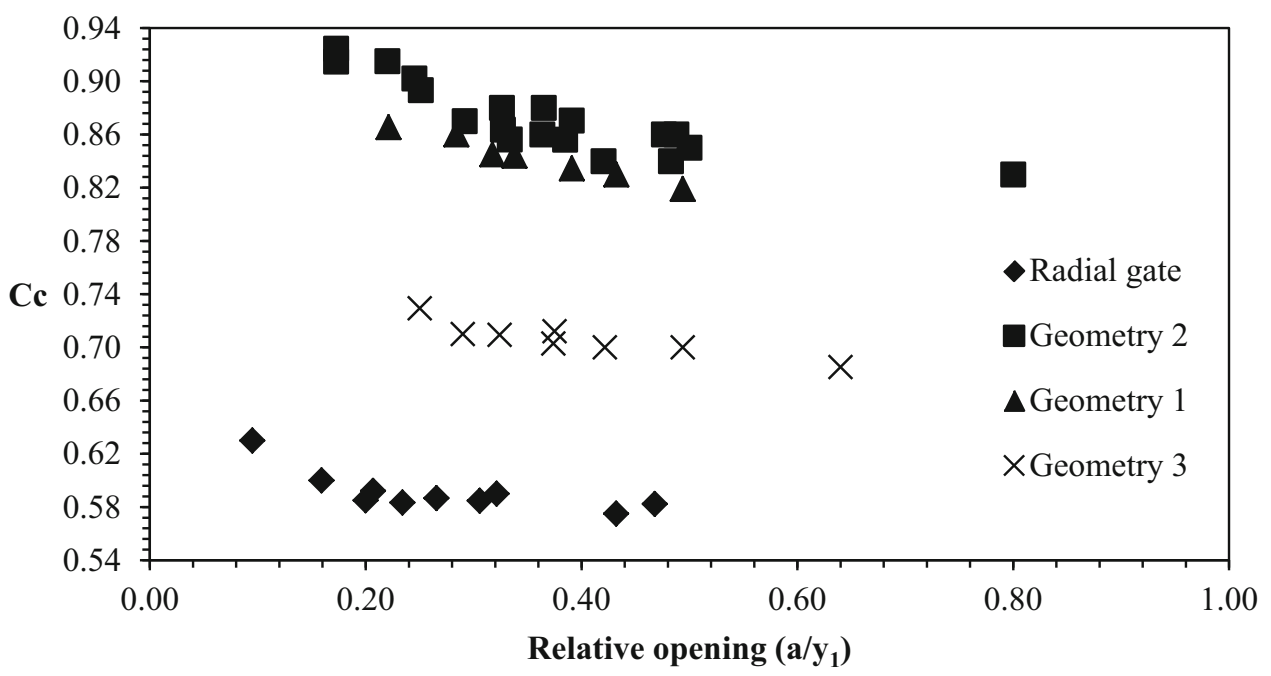

Figure 7. Coefficient of contraction as a function of relative gate opening in free flow.

shows the variation of $(1+\beta)$ with the Reynold's number defined well upstream of the gate.

$$
R_{e}=v_{1} H_{1} / v
$$

where $R_{e}$ is the Reynold's number; $v_{1}$ the average velocity upstream of the gate; $v$ the kinematic viscosity of water.

The trend obtained in the present study is consistent with the previous work done [15]. This suggests that the values of $(1+\beta)$ are higher for laboratory conditions as $H_{1}$ is lower and hence Reynolds number $\left(v H_{1} / v\right)$ is lower. Lower value of $(1+\beta)$ indicate a more uniform velocity distribution across the section. Experiment has been repeated for a different pinion height and similar results have been obtained.
The details of the experiments for the modified geometries are listed in table 1 and the results are shown in figure 10. From the graphs, the values of $C_{v}$ is obtained as $0.85,0.86$ and 0.86 for the modified geometries. The results suggest that the coefficient of velocity values are not affected much with the change in geometry.

\subsection{Contraction coefficient in submerged flow}

The variation of $C_{c}$ with relative gate opening for radial gate and the modified geometries are shown in figure 11 . The $C_{c}$ values for radial gate in the present study ranges from 0.55 to 0.75 . The experiments conducted by [23] 


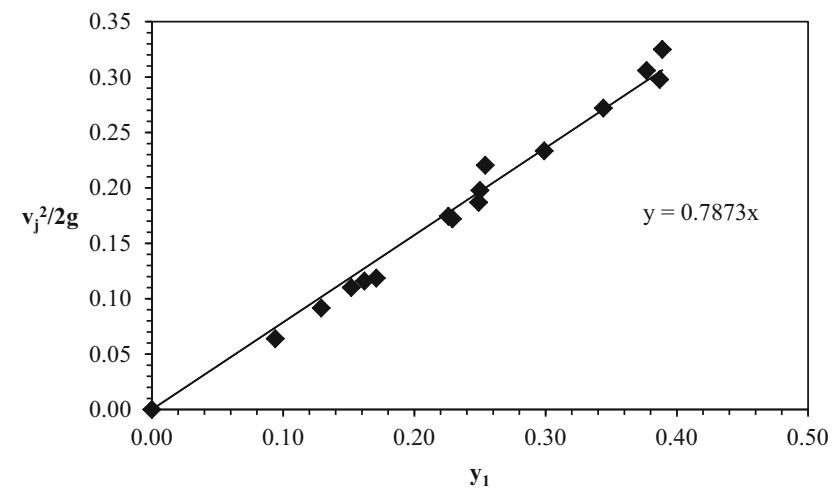

Figure 8. Variation of jet velocity with upstream depth for a radial gate under free flow conditions.

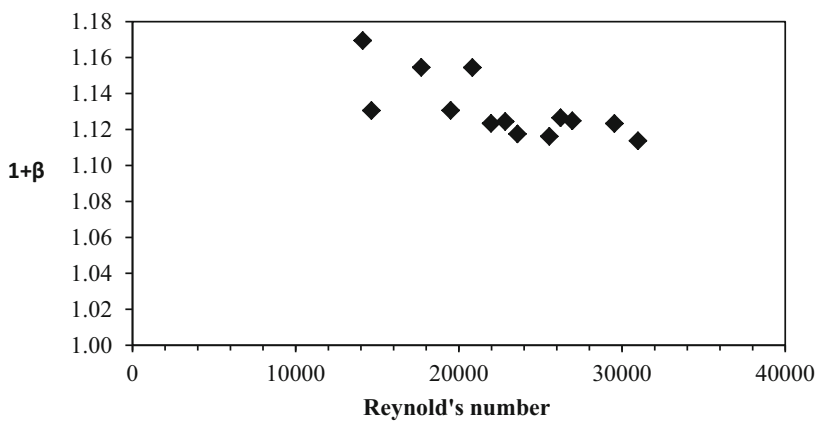

Figure 9. Variation of combined velocity distribution and energy loss coefficient with Reynold's number.

showed that the coefficient ranged from 0.62 to 0.724 for radial gates. The $C_{c}$ values show an increase with increase in the relative gate opening and these results are consistent with the experimental results as reported in [9] and also the numerical results as reported in [15]. Although modified gates with geometry 1 and 2 had a higher $C_{c}$ value, it was found that with geometry 1 the flow was unsteady downstream of the gate for higher discharges. Hence velocity

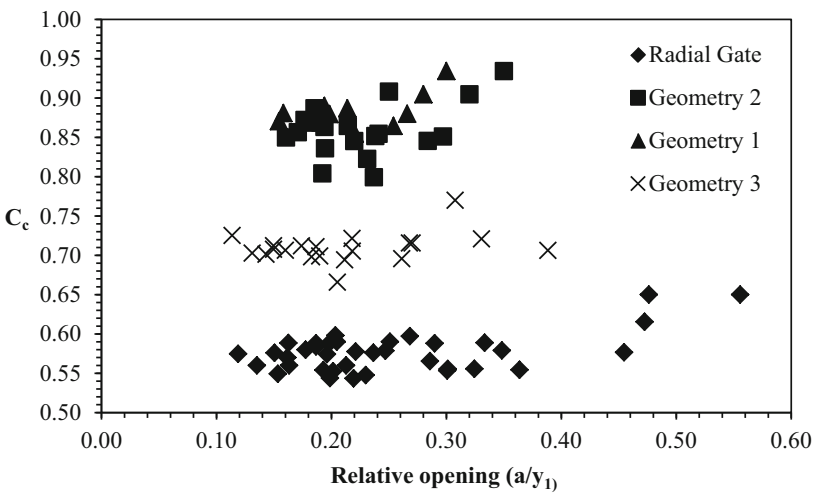

Figure 11. Variation of contraction coefficient with relative gate opening under submerged flow conditions.

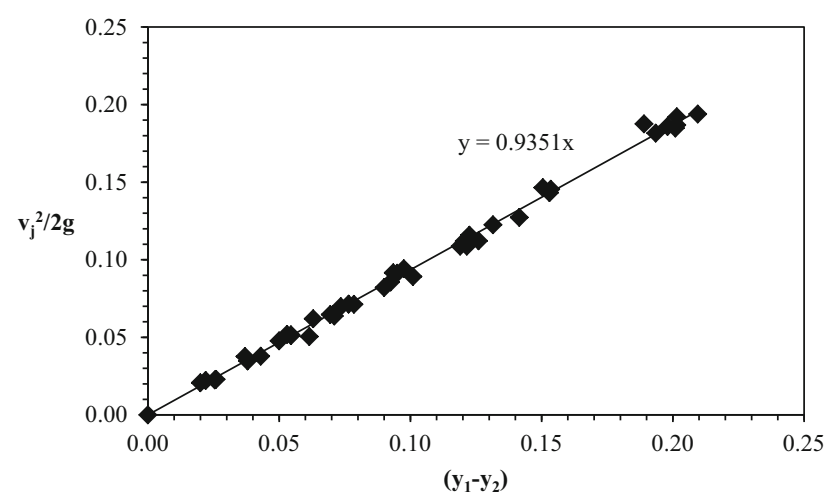

Figure 12. Variation of jet velocity with differential head for a radial gate in submerged flow.

measurements using ADV were not possible for the modified gate with geometry 1 for higher flows $(>30 \mathrm{l} / \mathrm{s}$ ). Modified radial gate with geometry 2 is found to perform better than the other two geometries in submerged conditions as well.

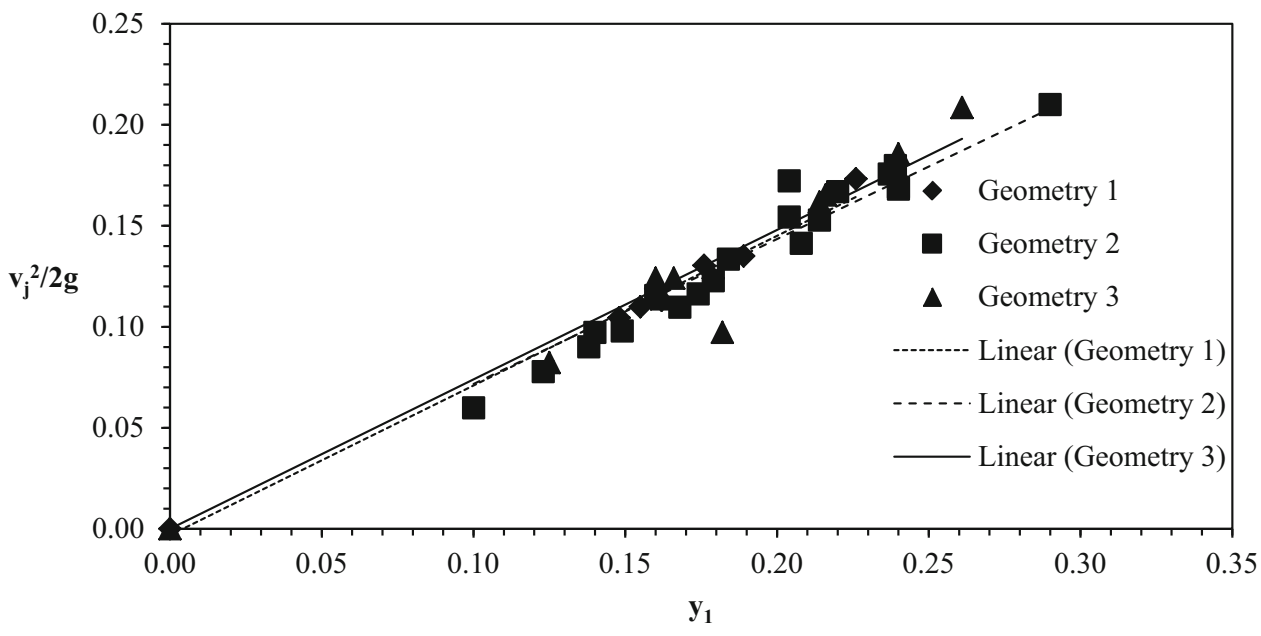

Figure 10. Variation of jet velocity with upstream depth for modified gates in free flow. 


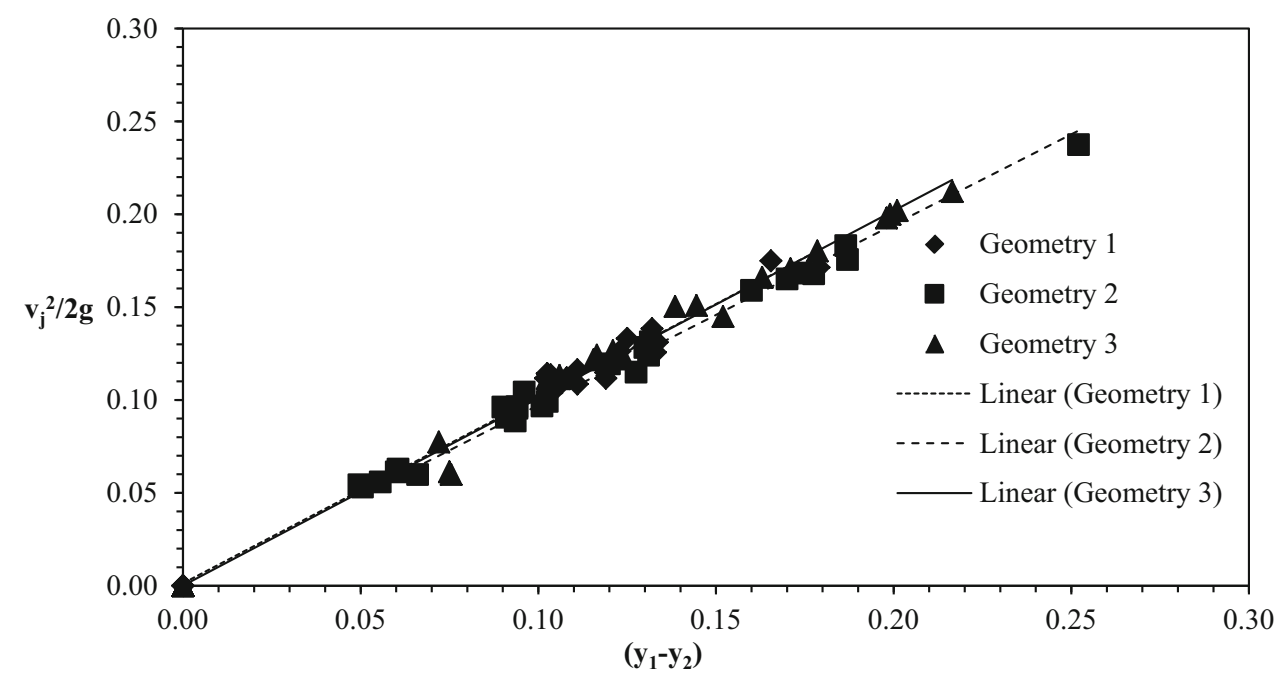

Figure 13. Variation of jet velocity with differential head for modified gates in submerged flow.

\subsection{Coefficient of velocity in submerged flow}

The variation of jet velocity with differential head under submerged flow is shown in figure 12 . With reference to figure 12 , the equation for the observed values for submerged flow is given by

$$
\frac{v_{j}^{2}}{2 g}=0.9351 *\left(y_{1}-y_{2}\right)
$$

From Eq. (13), the coefficient of velocity $C_{v}$ is found to be 0.967.The energy equation applied between upstream of the gate and the vena contracta for submerged flow condition with reference to figure 1 is given by

$$
H_{1}=y_{2}+\propto \frac{v_{j}^{2}}{2 g}+\beta \frac{v_{j}^{2}}{2 g}
$$

where $y_{2}$ is the depth downstream at the exit of the gate. The computed value of the combined velocity distribution coefficient and energy loss co-efficient for submerged flow varied from 1.0 to 1.11 . This value is less than that of the free flow suggesting that the losses encountered in free flow is more than in the submerged flow conditions. The variation of the jet velocity as a function of differential head for submerged flow conditions for the modified geometries are shown in figure 13. The scatter of points for geometry 1 in figure 13 may be due to the unsteady nature of the flow downstream side of the gate.

\section{Conclusions}

The coefficient of velocity $\left(C_{v}\right)$ and the coefficient of contraction $\left(C_{c}\right)$ were determined using jet velocity measured within the potential core of the wall jet for both free and submerged flow conditions. The results show that $C_{v}$ values are higher for submerged flows in comparison with free flows. This is due to lower energy loss coefficient $\beta$ in submerged flows.

The radial gate design has been modified with the intention of improvising the discharge characteristics. The experimental results on modified geometries show improved coefficient of contraction values when compared to that of the radial gate. Quadrants of an ellipse with three different dimensions were attached at the lip of the radial gate. The geometry with a ratio of 1:5 between the semi major axis of the quadrant to the radius of gate have better discharge characteristics as the contraction coefficient $C_{c}$ values were found to be higher in this case. The modification in the gate may obviate the need for additional rubber seals at the bottom of the gate as the stress concentration at the edge of the gate is likely to be reduced with the modification. Further experimental studies are required to confirm the reduction in stress concentration.

\section{List of symbols}

\section{a height of gate opening}

b length of the semi minor axis of the quadrant lip

$C_{c} \quad$ coefficient of contraction of the gate

$C_{v} \quad$ coefficient of velocity

$C_{d w} \quad$ coefficient of discharge of the weir

d length of the semi major axis of the quadrant lip

$g \quad$ acceleration due to gravity

$\mathrm{H}$ difference in manometer readings in the u-tube

$H_{w} \quad$ head over the crest of the weir

$H_{1} \quad$ upstream energy head

$L \quad$ width of the channel and length of the weir

$\mathrm{P}$ height of the weir

$\mathrm{p}$ pinion height of the gate 
$Q_{\text {act }}$ actual discharge in the flume

$\mathrm{R}$ radius of the radial gate

$R_{e} \quad$ Reynolds number

$v \quad$ velocity downstream of the gate

$v_{j} \quad$ jet velocity

$v_{1} \quad$ average velocity upstream of the gate

$y$ depth of water immediately downstream of the gate

$y_{j} \quad$ depth of water at the vena-contracta

$y_{1} \quad$ depth of water upstream of the gate

$y_{2}$ depth of water downstream at the exit of the gate

$y_{3} \quad$ tail water depth in the flume

$\alpha \quad$ velocity distribution coefficient

$\beta \quad$ energy loss coefficient

$v \quad$ kinematic viscosity

$\theta \quad$ gate angle

\section{References}

[1] Henry H R 1950 Discussion of diffusion of submerged jets. Trans. Am. Soc. Civ. Eng. 115(1): 665-693

[2] Rajaratnam N and Subramanya K 1967 Flow equation for the sluice gate. J. Irrig. Drain Division. 93(3): 167-186

[3] Swamee P K 1992 Sluice-gate discharge equations. J. Irrig. Drain. Eng. 118(1): 56-60

[4] Montes J S 1997 Irrotational flow and real fluid effects under planar sluice gates. J. Hydraul. Eng. 123(3): 219-232

[5] Ferro V 2000 Simultaneous flow over and under a gate. $J$. Irrig. Drain Eng. 126(3):190-193

[6] Ferro V 2001 Closure of simultaneous flow over and under a gate. J. Irrig. Drain Eng. 127(5): 325-328

[7] Lin C H, Yen J F and Tsai C T 2002 Influence of sluice gate contraction coefficient on distinguishing condition. J. Irrig. Drain Eng. 128(4): 249-252

[8] Lozano D, Mateos L, Merkley G P and Clemmens A J 2009 Field calibration of submerged sluice gates in irrigation canals. J. Irrig. Drain Eng. 135(6): 763-772

[9] Belaud G, Cassan L and Baume J P 2009 Calculation of contraction coefficient under sluice gates and application to discharge measurement. J. Hydraul. Eng. 135(12): 1086-1091

[10] Sepúlveda C, Gómez M and Rodellar J 2009 Benchmark of discharge calibration methods for submerged sluice gates. $J$. Irrig. Drain Eng. 135(5): 676-682

[11] Cassan L and Belaud G 2011 Experimental and numerical investigation of flow under sluice gates. J. Hydraul. Eng. 138(4): 367-373

[12] Castro-Orgaz, O Lozano D and Mateos L 2010 Energy and momentum velocity coefficients for calibrating submerged sluice gates in irrigation canals. J. Irrig. Drain Eng. 136(9): 610-616

[13] Habibzadeh A, Vatankhah A R and Rajaratnam N (2011) Role of energy loss on discharge characteristics of sluice gates. J. Hydraul. Eng. 137(9): 1079-1084

[14] Buyalski C P 1983 Discharge algorithms for canal radial gates (No. 627.13 B8). Engineering and Research Centre, U.S. Bureau of Reclamation, Denver

[15] Clemmens A J, Strelkoff T S and Replogle J A 2003 Calibration of submerged radial gates. J. Hydraul. Eng. 129(9): 680-687

[16] Wahl T L 2005 Refined energy correction for calibration of submerged radial gates. J. Hydraul. Eng. 131(6): 457-466

[17] Shahrokhnia M A and Javan M 2006 Dimensionless stagedischarge relationship in radial gates. J. Irrig. Drain Eng. 132(2): 180-184

[18] Bijankhan M, Ferro V and Kouchakzadeh S 2012 New stagedischarge relationships for radial gates. J. Irrig. Drain Eng. 139(5): 378-387

[19] Replogle J A, Adler R and Gooch R S 2003 Operational evaluations of new radial gate design. Water for a sustainable world-limited supplies and expanding demand In: Proceedings of 2nd International Conference on Irrigation and Drainage, Phoenix, AZ

[20] Pani B S 2012 Turbulent jets. Foundation Books: 186

[21] Tel J 2000 Discharge relations for radial gates. Master of Science Thesis, Delft Technical University, Delft

[22] Rusello P J, Lohrmann A, Siegel E and Maddux T 2006 Improvements in acoustic Doppler velocimetery, Food and Agricultural organisation of United Nations, http://www. ifremer.fr/avano/

[23] Speerli J and Hager W H 1999 Discussion of irrotational flow and real fluid effects under planer gates, by $\mathrm{J} S$ montes. $J$. Hydraul. Eng. 125(2): 208-213 